\section{A mutation in a mitochondrial transmembrane protein is responsible for the pleiotropic hematological and skeletal phenotype of flexed-tail ( $f / f)$ mice}

\author{
Mark D. Fleming, 1,2,5,7 Dean R. Campagna, 1,2 \\ Judith N. Haslett, ${ }^{3}$ Cameron C. Trenor III, ${ }^{2,4}$ \\ and Nancy C. Andrews ${ }^{2,4,6}$

\begin{abstract}
${ }^{1}$ Department of Pathology, ${ }^{2}$ Division of Hematology, ${ }^{3}$ Division of Genetics, and ${ }^{4}$ Howard Hughes Medical Institute, Children's Hospital, Boston, Massachusetts 02115, USA; ${ }^{5}$ Department of Pathology and ${ }^{6}$ Department of Pediatrics, Harvard Medical School, Boston, Massachusetts 02115, USA
\end{abstract}

We have studied the flexed-tail $(f)$ mouse to gain insight into mammalian mitochondrial iron metabolism. Flexed-tail animals have axial skeletal abnormalities and a transient embryonic and neonatal anemia characterized by pathologic intramitochondrial iron deposits in erythrocytes. Mitochondrial iron accumulation is the hallmark of sideroblastic anemias, which typically result from defects in heme biosynthesis or other pathways that lead to abnormal erythroid mitochondrial iron utilization. To clone the $f$ gene, we used positional cloning techniques, and identified a frameshift mutation in a mitochondrial transmembrane protein. The mutated gene, $S f_{x n 1}$, is the prototype of a novel family of evolutionarily conserved proteins present in eukaryotes.

Received December 12, 2000; revised version accepted January 26, 2001.

The flexed-tail $(f)$ mutation was originally studied for its variable spinal flexions that result from abnormalities in the developing intervertebral disks, particularly within the tail segments (Fig. 1A; Hunt et al. 1933; Kamenoff 1935). Later, the anemia was investigated thoroughly and found to be associated with microcytic, hypochromic red blood cells containing Prussian blue positive iron granules (Fig. 1B,C; Mixter and Hunt 1933; Grüneberg 1942a,b). Subsequent electron microscopic studies localized the iron deposits to mitochondria (Fig. 1D; Chui et al. 1977). The penetrance of the flexed tail and a white belly spot, another feature of the mutation, are highly variable on different genetic backgrounds; the anemia is the only fully penetrant feature on all genetic backgrounds.

[Key Words: flexed-tail; mouse; anemia; iron; sideroblast; mitochondria] Corresponding author.

E-MAIL mark.fleming@tch.harvard.edu; FAX (617) 566-5977.

Article and publication are at www.genesdev.org/cgi/doi/10.1101/ $\operatorname{gad} .873001$.
Unlike sideroblastic anemias (SAs) in man, the siderotic granules in $f / f$ animals are present in erythrocytes and are absent in nucleated erythroid precursors, and are thus properly called siderocytes, rather than sideroblasts. Furthermore, although inherited SAs in humans are lifelong, the siderocytes and anemia in $f / f$ animals are transient (Grüneberg 1942a,b). Developmental studies have shown that the anemia first becomes significant on embryonic day 12 (E12) (Grüneberg 1942b; Tarbutt and Cole 1972), coinciding with the onset of hepatic erythropoiesis. Mitochondrial iron deposits are not seen in primitive nucleated erythrocytes that circulate earlier in gestation. The anemia is most severe at E15 and persists through the second week of postnatal life. Amelioration of the anemia coincides with the disappearance of siderocytes from the peripheral blood as well as with the physiologic cessation of erythropoietic activity in the liver. As some forms of SA are associated with heme biosynthetic defects (for review, see Bottomley 1999), the siderotic mitochondria suggested a defect in heme biosynthesis. Fetal $f / f$ reticulocytes, but not adult reticulocytes or nucleated erythroid precursors, have reduced heme synthesis (Kreimer-Birnbaum et al. 1972; Cole et al. 1974, 1975). However, it is uncertain if this is a cause or a consequence of mitochondrial dysfunction.

Several lines of evidence suggest that the hematologic phenotype is not entirely restricted to erythrocytes produced by the fetal liver. A small number of siderocytes persist into adulthood, indicating the continued production of abnormal cells (Grüneberg 1942a). A latent abnormality in erythropoietic reserve can be unmasked in adults under conditions of erythropoietic stress, including phlebotomy and phenylhydrazine-induced hemolysis (Coleman et al. 1969). Spleen colony forming unit (CFU) assays also indicate an erythroid precursor defect (Thompson et al. 1966; Fowler et al. 1967; Bateman and Cole 1972; Gregory et al. 1975; Cole and Regan 1976). Adult bone marrow and fetal liver cells from $f / f$ and wildtype mice generate similar numbers of spleen colonies when injected into lethally irradiated hosts. However, the colonies obtained from $f / f$ donors are smaller, and contain proportionally fewer erythroid precursors (Thompson et al. 1966; Fowler et al. 1967). These studies indicate that there is a transplantable hematopoietic defect that is restricted to the erythroid compartment.

In order to further characterize the pathogenesis of the flexed-tail phenotype, and the erythroid defect in particular, we sought to determine the molecular basis of the $f$ mutation. Using positional cloning techniques, we identified a frameshift mutation in flexed-tail animals in a mitochondrial multiple transmembrane protein that is a member of a novel family of putative transport proteins present in eukaryotes.

\section{Results}

Flexed-tail had been mapped previously to mouse chromosome 13 using segregation of visible phenotypes. 


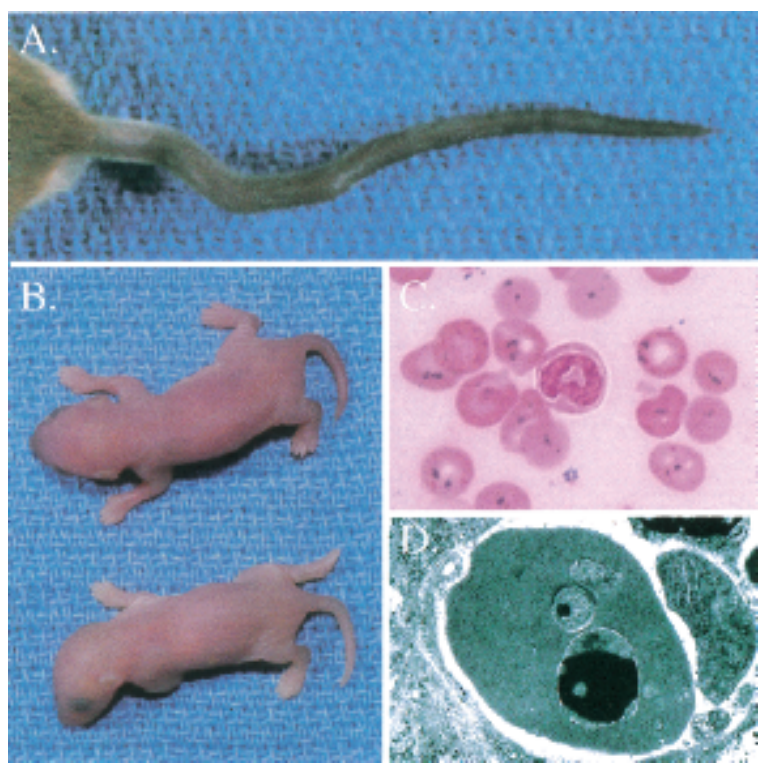

Figure 1. Flexed-tail $(f / f)$ phenotype. $(A)$ Variable tail curvatures seen in $f / f$ animals. (B) Pale newborn homozygous $f / f$ animal (below) and heterozygous $f /+$ littermate (above). (C) Prussian blue iron-stained peripheral blood smear from a newborn $f / f$ animal. Iron appears as dark blue granules seen in nearly all erythrocytes. $(D)$ Transmission electron micrograph of a newborn $f / f$ erythrocyte. A large electron-dense (black) inclusion can be seen in the mitochondrion at the bottom, and a smaller inclusion seen in the mitochondrion in the middle. This electrondense material is typical of the appearance of iron, which was confirmed by electron energy loss spectroscopy (EELS, data not shown).

This region does not correspond to the location of any genes encoding proteins previously known to be involved in mitochondrial heme or iron metabolism. We defined the map position to lie between the microsatellite markers D13Mit115 and D13Mit186, using homozygosity by descent mapping in flexed-tail congenic lines (Wevrick et al. 1993; Fleming et al. 1997). Multiple backcrosses segregating $f$ were analyzed to further localize the gene. An intersubspecific backcross with CAST/Ei was most informative (Fig. 2A). Using this cross, we initially localized $f$ to a 1.5 -cM genetic interval between the genes Drd1a and Hrh2. A bacterial artificial chromosome (BAC) contig including these genes was constructed (Fig. 2B). BAC end sequences were used to create additional markers, which further narrowed the genetic interval. One BAC end sequence was homologous to multiple mouse expressed sequence tags (ESTs) derived from a single gene. The genomic sequence for this gene, totaling approximately $35 \mathrm{~kb}$ (Fig. 2C), was used to develop additional novel polymorphic markers. When mapped in the CAST/Ei backcross, markers located within intron 1 and within the $3^{\prime}$ untranslated region of the gene were found to flank the $f$ locus on the centromeric and telomeric sides, respectively (Fig. 2A,C).

Through sequence analysis of genomic and RT-PCR clones of this gene, which we have named sideroflexin 1 (Sfxn1) for the siderocytic anemia and flexed tail pheno- types, we found a single base (adenine) insertion within the coding sequence in all $f$ mutant congenic lines. This insertion, located in exon 2 of $S f \times n 1$, was not present in 19 genetically diverse wild-type mouse strains, and was also nonrecombinant with the phenotype when mapped in the backcrosses (Fig. 2A,C). The predicted open reading frame of $S f_{x n} 1$ contains 322 amino acids. The mutation occurs after codon 15, and is predicted to cause a frameshift that would result in a truncated abnormal peptide consisting of 15 amino acids of the wild-type protein followed by 17 novel amino acids before an inframe stop codon. To determine whether $f / f$ animals produce Sfxn1 protein, we raised a rabbit antiserum against mouse Sfxn1. Western blots of protein extracts from multiple tissues from wild-type and $f / f$ mice revealed a protein in wild-type, but not $f / f$ animals (Fig. 3A).

The only fully penetrant phenotype in $f / f$ animals is the accumulation of iron in erythroid mitochondria. For that reason, we anticipated that Sfxn1 would be a mitochondrial protein. To evaluate its subcellular localization, we expressed an epitope-tagged form of the protein in HEK293T human embryonic kidney cells. The tagged protein colocalized with MitoTracker Red CMXRos (Molecular Probes), which concentrates in mitochondria (Fig. 3B). Western blotting of mitochondrial fractions of transfected cells probed with an antibody directed against the epitope tag as well as the antigen-specific

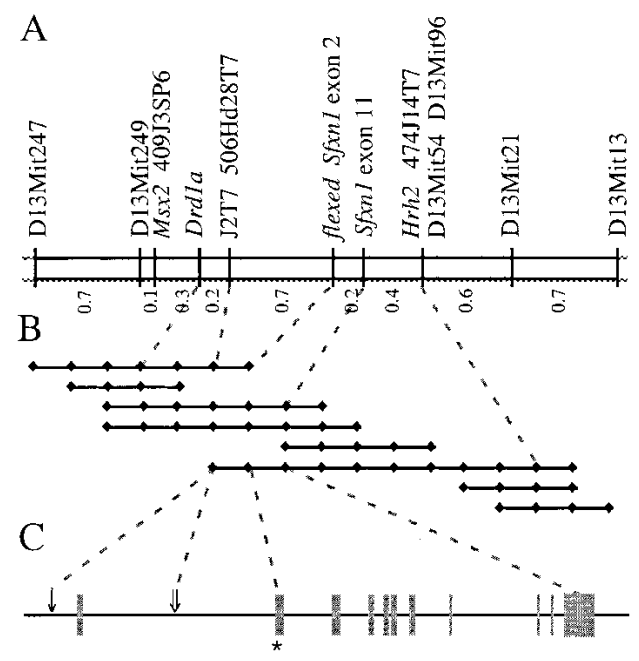

Figure 2. Genetic and physical maps of the flexed-tail region. (A) Genetic map of the $f$ locus on mouse chromosome 13 determined from 1000 CAST/Ei backcross animals. PCR polymorphism markers are listed above, and recombination distances in centimorgans (cM) are below. $(B)$ Bacterial artificial chromosome (BAC) contig spanning the $f$ critical genetic interval. Individual sequence tagged sites (STSs) present on each BAC are indicated by black diamonds. STSs mapped in the backcross are indicated by a dashed line. $(C)$ The intron/exon structure of the $S f \times n 1$ gene. The gene spans approximately $35 \mathrm{~kb}$ and is divided into 11 exons (gray boxes). Exon 2, which was nonrecombinant with the phenotype in the backcrosses and contains the $f$ mutation, is indicated by an asterisk. The position on the physical map of the centromeric flanking markers J2T7 and 506 Hd28T7 are indicated by a single arrow and a double arrow, respectively. 


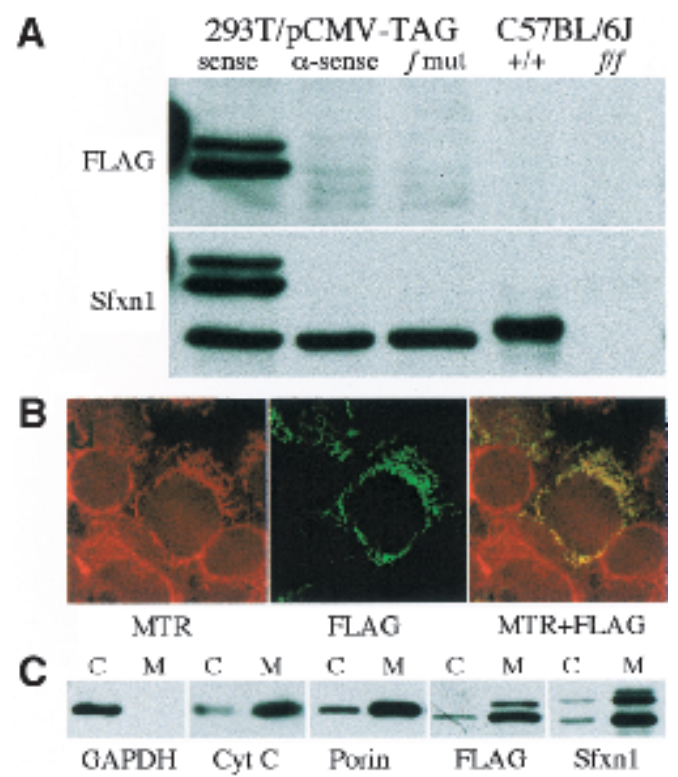

Figure 3. Western blotting and subcellular localization of Sfxn1. (A) Western blots from HEK293T cells transfected with epitope-tagged (FLAG) wild-type $S f_{X n 1} 1$ cloned in a sense and antisense $(\alpha$-sense) orientation, as well as the $f$ frameshift mutation $(f$ mut $)$, and on kidney tissue extracts from wild-type $(+/+)$ and $f / f$ animals on a C57BL/6J background. The FLAG-tagged protein runs as a doublet with an apparent molecular mass 4-6 $\mathrm{kD}$ greater than the endogenous human or mouse proteins. $(B)$ HEK293T cells were transfected with FLAG-tagged Sfxn1 and pulsed with MitoTracker Red CMXRos (MTR). Colocalization of the epitope-tagged protein and mitochondria is seen as yellow fluorescence in the red and green merged image (MTR + FLAG). (C) Western blots of whole cell extracts (c) and purified mitochondria $(\mathrm{m})$ from transfected HEK293T cells using antibodies against the cytoplasmic enzyme GAPDH, and the mitochondrial proteins porin and cytochrome $\mathrm{C}(\mathrm{Cyt} \mathrm{C})$.

antiserum, confirmed the mitochondrial localization determined by immunofluorescence (Fig. 3C).

Northern blot analysis shows that SfXn1 mRNA is widely expressed, but present in the highest levels in adult kidney and liver (Fig. 4). The expression pattern in the mouse embryo varies with the stage of development; however, very high levels of mRNA are present in the liver during the period of embryonic hepatic erythropoiesis when the $f / f$ phenotype is most conspicuous (data not shown). Also consistent with the siderocytic phenotype, $S f_{x n 1}$ mRNA and protein are abundant in murine erythroleukemia (MEL) cells (data not shown). Sfxn1 mRNA expression is not altered in $f / f$ animals (data not shown).

Sfxn1 is predicted to have five transmembrane domains, suggesting that it may be a channel or carrier molecule (Fig. 5). Motif searches revealed no canonical mitochondrial targeting signal or other common structural motif. The orthologous rat protein has been suggested to be a mitochondrial tricarboxylic acid carrier (Azzi et al. 1993), but functional studies using heterologously expressed protein have not been performed to substantiate this activity. However, it seems unlikely that Sfxn1 has that function, because another mitochondrial protein, which is a member of the mitochondrial carrier family $(\mathrm{MCF})$, has been conclusively shown to transport tricarboxylic acids (Xu et al. 1995). Furthermore, a protein with a molecular weight similar to this MCF protein appears to copurify with the rat Sfxn1 protein, suggesting how the function of Sfxnl may have been misidentified (Azzi et al. 1993). For these reasons, the designation of Sfxn1 as a tricarboxylic acid carrier is substantially in doubt.

Sfxn1 protein bears no homology to any other protein of known function. Using sequence database searches we have found that Sfxn 1 is a member of a family of proteins found in organisms ranging from yeast to mammals. The Caenorhabditis elegans, Drosophila melanogaster, and Saccharomyces cerevisiae sequencing projects predict seven, two, and one homologous genes, respectively (Fig. 5; data not shown). Examination of mammalian EST and genomic databases reveals four additional mouse homologs and their human counterparts (Fig. 5). All of these proteins share a similar predicted transmembrane structure and contain contiguous blocks of conserved amino acids. Mouse Sfxn1 is most closely related to Sfxn3, which is $79 \%$ similar and $70 \%$ identical. The homologous yeast open reading frame (YOR271c) is 55\% similar and $37 \%$ identical to mouse Sfxn 1 and is more closely related to mouse Sfxn5. Northern blots of these genes in adult mouse tissues reveal partially overlapping patterns of expression (Fig. 4). Expression of $S f \times n 2$, similar to $S f_{X n 1}$, is at particularly high levels in adult kidney and liver. $S f_{x n 3}$ is present in most tissues examined; whereas $S f_{x n} 4$ is largely restricted to kidney, brain, and heart; and $S f x n 5$ to liver and brain.

\section{Discussion}

Recent advances in the field of iron metabolism have illuminated many of the basic processes of iron absorption and distribution in mammals (for review, see Andrews 2000). However, many aspects of intracellular iron metabolism remain obscure. The mechanisms of iron transport to and within mitochondria, where iron is incorporated into protoporophyrin IX to form heme, have

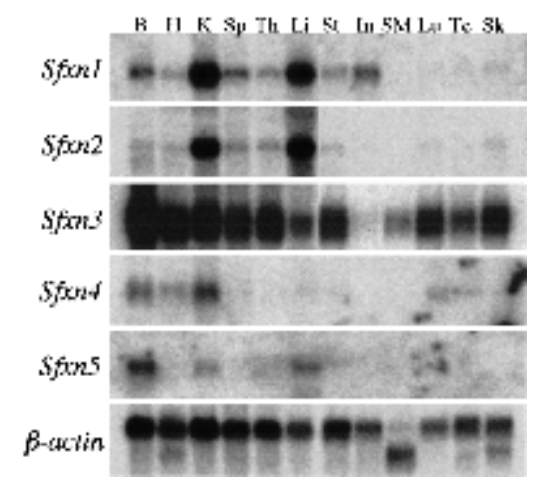

Figure 4. Expression of mouse sideroflexin homolog mRNAs. $\mathrm{B}$, brain; H, heart; K, kidney; Sp, spleen; Th, thymus; Li, liver; St, stomach; In, intestine; SM, skeletal muscle; Lu, lung; Te, testis; Sk, skin. 


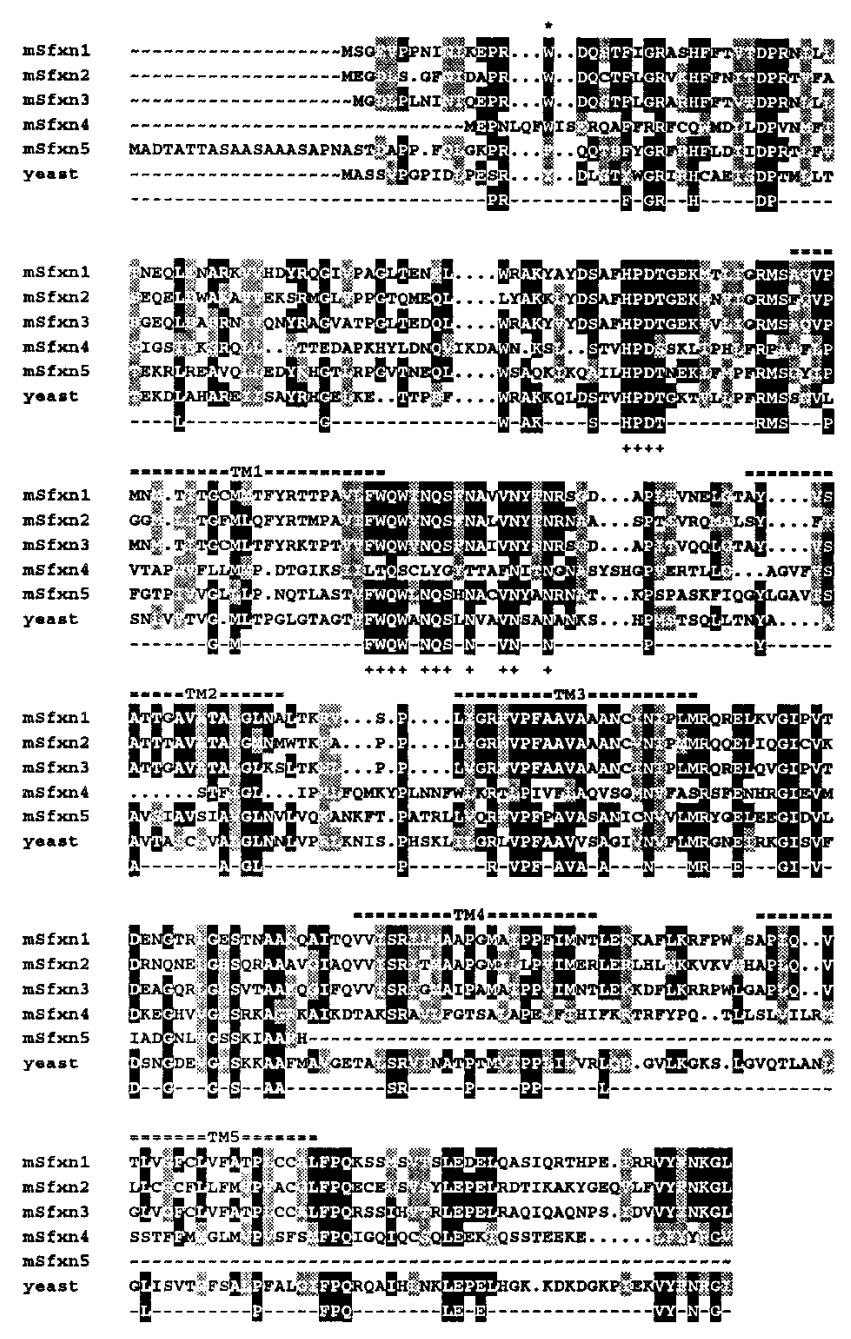

Figure 5. Peptide alignment of mouse and yeast sideroflexin homologs. Amino acids conserved in $60 \%$ or more of the sequences are shaded black, but only those present in $80 \%$ or more of the sequences are represented in the consensus sequence. Similar amino acids present in $>60 \%$ of sequences are shaded gray. Based upon its human counterpart, the mouse sideroflexin 5 sequence is a partial sequence truncated at the carboxy terminus. Predicted transmembrane domains (TM) are indicated by a double bar above the sequence alignment. The particularly well-conserved HPDT and asparagine-rich motifs are indicated by plus signs $(+)$ under the sequences. The site of the $f$ frameshift mutation is marked by an asterisk.

been particularly elusive. By definition, sideroblastic anemias share the morphologic feature of pathologic intramitochondrial iron deposits in erythroid precursors, indicating that they interrupt mitochondrial iron utilization (for review, see Bottomley 1999). The best-characterized form of SA, X-linked sideroblastic anemia (XLSA), is an inherited defect in the erythroid-specific form of the heme biosynthetic gene $\delta$-aminolevulinic acid synthetase (ALAS2). A variety of toxins and deficiency states that are associated with SA in humans, including isoniazid and lead toxicity, and pyridoxine deficiency, cause SA by inhibiting heme biosynthesis. Another rare, inherited form of SA, X-linked sideroblastic anemia with ataxia (XLSA/A), is the consequence of missense mutations in $A B C 7$, which is a mitochondrial protein thought to participate in the maturation of cytoplasmic iron-sulfur proteins (Bekri et al. 2000). In other genetic and acquired forms of SA, such as Pearson marrow-pancreas syndrome, chloramphenicol toxicity, and primary myelodysplastic syndromes, the pathogenetic mechanisms leading to the development of sideroblasts are unknown. Several families with autosomal dominant or recessive SA have been described (see, for example, van Waveren Hogervorst et al. 1987). The SA phenotype has not been reported to coexist with skeletal or pigmentary abnormalities in any of these families. Nonetheless, SFXN1 could be considered a candidate gene for these inherited anemias.

The flexed-tail mutation is the only viable animal model of inherited SA in which mitochondrial iron accumulation recapitulates the erythroid mitochondrial iron deposition seen in humans. Zebrafish with mutations in Alas2 lack sideroblasts (Brownlie et al. 1998), and a mouse Alas2 null mutant is not viable (Harigae et al. 1998; Nakajima et al. 1999). Given what is known about the pathogenesis of SA and the predicted structural features of Sfxn1, it is likely that the protein facilitates the transport of a component required for iron utilization into or out of the mitochondria. An abundance of iron-laden mitochondria in mature anucleate erythrocytes (siderocytes) is distinctive among the SAs, and, outside of the $f / f$ mutant, has been described only in severely pyridoxine-deficient juvenile swine or neonatal rodents (Deiss et al. 1966; Hammond et al. 1969; Keyhani et al. 1974). This suggests that pyridoxine, or a derivative thereof, may be transported by Sfxn1 into the mitochondria. Pyridoxine is a cofactor for ALAS2, and siderotic granules in pyridoxine deficiency are presumed to develop as a consequence of ALAS2 deficiency. Why pyridoxine deficiency should result in siderocytes in these animal models, yet cause sideroblasts in humans, is uncertain, but may reflect species-specific differences in mitochondrial heme metabolism or iron incorporation in erythroid development.

The transience of the siderocytes and the anemia are also distinctive features of the flexed-tail phenotype. The erythroid abnormalities are first noted at the onset of fetal liver hematopoiesis, reach their peak during the period in which the liver is the sole site of erythropoiesis, and gradually disappear as other tissues subsume this function. Given the temporal coincidence of abnormal erythrocytes with embryonic hepatic erythropoiesis, it appears that Sfxn 1 is particularly important for this class of erythrocytes. Sfxn1 could play a role unique to erythrocytes originating from the embryonic liver. Alternatively, there may be no functionally redundant protein in these cells. In addition, the exceptionally large flux of potentially toxic iron through erythroid mitochondria, compared to that in mitochondria of other cells, may precipitate the mitochondrial pathology. The presence of at least four homologous mouse proteins, some of which appear to localize to mitochondria (M.D. Fleming, unpubl.), suggests that functional redundancy is likely. 
Similarly, the skeletal and belly spotting phenotypes could be caused by a relative or absolute lack of sideroflexin activity during periods critical to the development of these tissues. The variable penetrance of the tail flexions and belly spots on different genetic backgrounds is likely owing to the segregation of alleles of modifier genes. The other mitochondrial sideroflexins are potential candidate genes for these modifiers.

The flexed-tail mutation shares the combination of a white belly spot and an erythroid precursor defect with another mouse mutant, dominant white spotting $(W)$, which has a mutation in the gene encoding the stem cell factor receptor Kit. Analysis of mice segregating both $f$ and $W$ showed a more severe anemic and spotting phenotype in animals homozygous for $f$ and heterozygous for $W$ compared to either mutant alone, raising the possibility that the protein products of these two loci might interact in the same pathway (Russell and McFarland 1966; Russell et al. 1968). The facts that Sfxn1 is present in mitochondria and Kit is located on the plasma membrane suggest that the increased severity of the double mutant is more likely an additive effect of abnormalities in two disparate pathways.

Sfxn1 is the first member of a novel family of eukaryotic transmembrane proteins to be identified. Comparison of the S. cerevisiae, C. elegans, D. melanogaster, mouse, and human Sfxn proteins shows conservation of a predicted five-transmembrane-domains structure. Each protein has a long $\mathrm{N}$ terminus that is relatively poorly conserved among family members. Blocks of particularly well-conserved contiguous amino acids are located immediately prior to and immediately after the first predicted transmembrane domain; an asparagine-rich motif, F-W-Q-W-N-Q-S-X-N-A-X-V-N-(Y)-X-N-R, and a fouramino-acid motif, H-P-D/E-T/S, are present in essentially all Sfxn homologs (Fig. 5; data not shown). Neither these motifs nor any other protein sequence element appear to be shared with other protein families. The high degree of homology between the yeast and other eukaryotic Sfxn proteins suggests that studies of the yeast sideroflexin homolog (ySH) may reveal a general function for this protein family. As determined by studies of yeast with a targeted disruption in $\mathrm{ySH}$, the protein is nonessential and does not lead to the respiratory abnormalities typically seen in yeast with mitochondrial iron overload (L. Li, J. Kaplan, and M.D. Fleming, unpubl.). Further characterization of this knockout yeast strain will be essential for elucidating the specific function of each of the sideroflexins and the mechanism of mitochondrial iron overload in the $f / f$ mouse.

\section{Materials and methods}

Mice and linkage experiments

The single allele of $f$ arose on a genetically undefined stock in 1927 and was subsequently transferred onto several genetic backgrounds to create the congenic and recombinant inbred lines Je/Le-f/f, ru/ru, je/+, FLl/ReJ WB/ReJ-f/f, and C57BL/6J-f/f. An ancestral $f$ haplotype common to each of the congenic lines was determined by comparing chromosome $13 \mathrm{mi}-$ crosatellite repeat alleles from the congenic $f$ and control strains. The relative positions of these markers were obtained from public databases (www.jax.org). For linkage experiments, congenic C57BL/6J-f/f mice, originally obtained at generation $\mathrm{N}_{27} \mathrm{~F}_{2}$ from the Jackson Laboratory (Bar Harbor, ME), were crossed to BALB/cByJ, CAST/Ei, SPRET/Ei, NZW/ LacJ, and C57BL/6J animals. $\mathrm{N}_{2}$ backcross pups were sacrificed at age 1-3 $\mathrm{d}$, and phenotypes were determined by inspection for pallor and by evaluation of an iron-stained (Sigma) peripheral blood smear for siderocytes. Tail DNA was prepared using the QIAmp tissue kit (Qiagen). A total of 2888 backcross animals (1728 CAST/Ei, 486 BALB/cByJ, 259 C57BL/6J, 212 SPRET/Ei, and $193 \mathrm{NZW/LacJ/} \mathrm{were} \mathrm{screened} \mathrm{for} \mathrm{crossovers} \mathrm{between}$ D13Mit247 and D13Mit13 or D13Mit21. Informative animals were typed with more closely linked markers. Whitehead/MIT markers were obtained from Research Genetics and assayed using standard ${ }^{32} \mathrm{P}$-end-labeled methodology. Other PCR marker primer pairs were developed from genomic sequences using the Primer 3 program (www.genome.wi.mit. edu) and a target melting temperature of $55^{\circ} \mathrm{C}$.

\section{Physical mapping}

Bacterial artificial chromosomes (BACs) were isolated by PCR screening the CITB Mouse BAC Library (Research Genetics) for Drd1a and Hrh2. $\mathrm{BAC}$ ends were sequenced using the Promega $\mathrm{fmol}$ PCR sequencing kit, and ${ }^{32} \mathrm{P}$-end-labeled primers. STSs were developed from each BAC end, and a contig of $\sim 300 \mathrm{~kb}$ was assembled from eight overlapping clones. Additional markers were derived from end sequences of bacteriophage $\lambda$ clones and plasmid subclones of one 140-kb BAC whose ends genetically flanked the phenotype.

cDNA cloning, mutation analysis, and Northern blotting

The SP6 end of mouse BAC clone $226 \mathrm{H} 13$ was homologous to multiple mouse expressed sequence tags (ESTs), including GenBank accession no. AI173256. Mouse Sfxn homologs were identified by iterative nucleotide and protein BLAST searches of the mouse EST database with mouse Sfxn1 and the yeast Sfxn homolog (GenBank accession no. SCYOR271c). ESTs containing cDNA inserts for Sfxn2 (GenBank accession no. AI196018), Sfxn3 (GenBank accession no. AA688613), Sfxn4 (GenBank accession no. AI182690), and Sfxn5 (GenBank accession no. AI099081) were confirmed by sequencing. Additional $S f \times n 2, S f \times n 4$, and $S f_{x n} 5$ sequences were obtained by screening a mouse newborn brain cDNA library (Stratagene) with EST probes. The mouse $S f x n$ sequences have been deposited in GenBank as accession numbers AF325260, AF325261, AF325261, AF325263, and AF325264. Protein homology alignments and secondary structure predictions were made with SeqWeb (GCG) and TMPred (www.ch.embnet.org). RT-PCR subclones were obtained from $\mathrm{C} 57 \mathrm{BL} / 6 \mathrm{~J}$ and $\mathrm{C} 57 \mathrm{BL} / 6 \mathrm{~J}-f / f\left(\mathrm{~N}_{27} \mathrm{~F}_{8}\right)$ animals (Topo-TA cloning kit, Invitrogen) using the primers 5'GGGTAGGCGGATCTGGGACG-3' and 5'CCGGCCTCCAGCACTTGATC-3'. Sf xn1 exon 2 sequences were amplified from genomic DNA from 19 diverse wild-type strains and all existing $f$ congenic lines using the primers 5 -GACAACTGTGAGAAG GTCCCA-3' and 5'-CACCACTTTCCTCGCATTCT-3', and analyzed by direct sequence analysis. Northern blotting was performed on an adult mouse multitissue Northern blot (Origene Technologies) by sequential hybridization with radiolabeled probes of the entire open reading frames of mouse $S f_{x n 1}, S f_{x n} 2, S f_{x n} 3, S f \times n 4$, and $\beta$-actin. The $S f_{x n} 5$ probe was homologous to the coding sequences for amino acids 1-141 of Sfxn1.

Subcellular localization

The open reading frame of $S f x n 1$ was cloned into pCMV-Tag4A (Stratagene) and transfected into HEK293T cells with Geneporter (Gene Therapy Systems). Transfected cells plated on cover slips were pulsed with $25 \mathrm{ng} / \mathrm{mL}$ MitoTracker Red CMXRos (Molecular Probes), and processed for immunofluorescence as described previously (Su et al. 1998). For subcellular fractionation studies, crude mitochondria were obtained by differential centrifugation of cell lysates and further purified using a sucrose step gradient (Spector et al. 1998).

Antibodies and Western blotting

A Sfxn1-specific antiserum was raised in rabbits by immunization with a mixture of three GST fusion proteins containing amino acids 12-272, $197-228$, and 292-322 of mouse Sfxn1. Immune serum was used for Western blots at a dilution of 1:1000. Reactivity was detected with alkaline phosphatase (AP)-conjugated donkey anti-rabbit serum (Amersham) at 1:20,000. Epitope-tagged proteins were detected with the monoclonal anti-FLAG M2 antibody (Kodak) at 1:10,000 and detected with AP-conjugated sheep anti-mouse antiserum at 1:5000 (Amersham). Each 
blot contained $25 \mu \mathrm{g}$ of cell or tissue lysate blotted onto Hybond P (Amersham). For mitochondrial fractionation, duplicate samples of $5 \mu \mathrm{g}$ of cellular and mitochondrial protein were blotted and detected with antibodies against GAPDH (1:1000; Advanced ImmunoChemical), porin (1: 5000; Calbiochem), cytochrome C (1:100; Molecular Probes), the FLAG epitope, and Sfxn1.

\section{Acknowledgments}

The authors thank Orian Shirihai for advice on mitochondrial purification, Liangtao Li and Jerry Kaplan for assistance in evaluating the yeast sideroflexin homolog, John Drago for providing the unpublished sequence of the murine Drd1a gene, and John Godleski for performing EELS spectroscopy. Jerry Kaplan, Adriana Donovan, and Bernard MatheyPrevot are acknowledged for critically reviewing the manuscript. This work was supported by NHLBI K08 HL03600 (M.D.F) and the Howard Hughes Medical Institute (N.C.A). C.C. Trenor III is presently a medical student at the University of Tennessee, Memphis.

The publication costs of this article were defrayed in part by payment of page charges. This article must therefore be hereby marked "advertisement" in accordance with 18 USC section 1734 solely to indicate this fact.

\section{References}

Andrews, N.C. 2000. Iron homeostasis: Insights from genetics and animal models. Nat. Rev. (Genetics) 1: 208-217.

Azzi, A., Glerum, M., Koller, R., Mertens, W., and Spycher, S. 1993. The mitochondrial tricarboxylate carrier. J. Bioenerg. Biomem. 25: 515524.

Bateman, A.E. and Cole, R.J. 1972. Colony forming cells in the livers of prenatal flexed $(f / f)$ anaemic mice. Cell Tissue Kinet. 5: 165-173.

Bekri, S., Kispal, G., Lange, H., Fitzsimons, E., Tolmie, J., Lill, R., and Bishop, D.F. 2000. Human ABC7 transporter: Gene structure and mutation causing $\mathrm{X}$-linked sideroblastic anemia with ataxia with disruption of cytosolic iron-sulfur protein maturation. Blood 96: 32563264.

Bottomley, S.S. 1999. Sideroblastic Anemias. In Wintrobe's clinical hematology (ed. G.R. Lee), pp. 1022-1045. Williams and Wilkins, Baltimore.

Brownlie, A., Donovan, A., Pratt, S.J., Paw, B.H., Oates, A.C., Brugnara, C., Witkowska, H.E., Sassa, S., and Zon, L.I. 1998. Positional cloning of the zebrafish sauternes gene: A model for congenital sideroblastic anaemia. Nat. Genet. 20: 244-250.

Chui, D.H., Sweeney, G.D., Patterson, M., and Russell, E.S. 1977. Hemoglobin synthesis in siderocytes of flexed-tail mutant $(f / f)$ fetal mice. Blood 50: 165-177.

Cole, R.J. and Regan, T. 1976. Haemopoietic progenitor cells in prenatal congenitally anaemic flexed-tailed $(f / f)$ mice. Br. J. Haematol. 33: 387-394.

Cole, R.J., Garlick, J., and Tarbutt, R.G. 1974. Disturbed haem and globin synthesis in reticulocytes of prenatal flexed-tailed $(f / f)$ anaemic mice. Genet. Res. 23: 125-135.

Cole, R.J., Garlick, J., and Cheek, E.M. 1975. Activities of haem synthetic enzymes in blood cells of pre-natal flexed-tailed $(f / f)$ anaemic mice. $J$. Embryol. Exp. Morphol. 34: 373-386.

Coleman, D.L., Russell, E.S., and Levin, E.Y. 1969. Enzymatic studies of the hemopoietic defect in flexed mice. Genetics 61: 631-642.

Deiss, A., Kurth, D., Cartwright, G.E., and Wintrobe, M.M. 1966. Experimental production of siderocytes. J. Clin. Invest. 45: 353-364.

Fleming, M.D., Trenor III, C.C., Su, M.A., Foernzler, D., Beier, D.R., Dietrich, W.F., and Andrews, N.C. 1997. Microcytic anemia mice have a mutation in Nramp2, a candidate iron transporter gene. Nat. Genet. 16: 383-386.

Fowler, J.H., Till, J.E., McCulloch, E.A., and Siminovitch, L. 1967. The cellular basis for the defect in haemopoiesis in flexed-tailed mice. II The specificity of the defect for erythropoiesis. Br. J. Haematol. 13: 256-264.

Gregory, C.J., McCulloch, E.A., and Till, J.E. 1975. The cellular basis for the defect in haemopoiesis in flexed-tailed mice. III. Restriction of the defect to erythropoietic progenitors capable of transient colony formation in vivo. Br. J. Haematol. 30: 401-410.
Grüneberg, H. 1942a. The anaemia of flexed-tail mice (Mus musculus 1.): I. Static and dynamic haematology. I. Genet. 43: 45-68.

Grüneberg, H. 1942b. The anaemia of flexed-tail mice (Mus musculus 1.): II. Siderocytes. I. Genet. 44: 246-271.

Hammond, E., Deiss, A., Carnes, W.H., and Cartwright, G.E. 1969. Ultrastructural characteristics of siderocytes in swine. Lab. Invest. 21: 292-297.

Harigae, H., Suwabe, N., Weinstock, P.H., Nagai, M., Fujita, H., Yamamoto, M., and Sassa, S. 1998. Deficient heme and globin synthesis in embryonic stem cells lacking the erythroid-specific $\delta$-aminolevulinate synthase gene. Blood 91: 798-805.

Hunt, H.R., Mixter, R., and Permar, D. 1933. Flexed tail in the mouse, Mus musculus. Genetics 18: 335-366.

Kamenoff, R.J. 1935. Effects of the flexed-tail gene on the development of the house mouse. J. Morphol. 58: 117-155.

Keyhani, M., Giuliani, D., Giuliani, E.R., and Morse, B.S. 1974. Erythropoiesis in pyridoxine deficient mice. Proc. Soc. Exp. Biol. Med. 146: 114-119.

Kreimer-Birnbaum, M., Bannerman, R.M., Russell, E.S., and Bernstein, S.E. 1972. Pyrrole pigments in normal and congenitally anaemic mice $\left(+/+, W / W^{v}, h a / h a, n b / n b, m k / m k, f / f\right.$ and $\left.s l a / Y\right)$. Comp. Biochem. Physiol. 43A: 21-30.

Mixter, R. and Hunt, H.R. 1933. Anemia in the flexed tailed mouse, Mus musculus. Genetics 18: 367-387.

Nakajima, O., Takahashi, S., Harigae, H., Furuyama, K., Hayashi, N., Sassa, S., and Yamamoto, M. 1999. Heme deficiency in erythroid lineage causes differentiation arrest and cytoplasmic iron overload. EMBO J. 18: 6282-6289.

Russell, E.S. and McFarland, E.C. 1966. Analysis of pleiotropic effects of $W$ and $f$ genic substitutions in the mouse. Genetics 53: 949-959.

Russell, E.S., Thompson, M.W., and McFarland, E.C. 1968. Analysis of effects of $W$ and $f$ genic substitutions on fetal mouse hematology. Genetics 58: 259-270.

Spector, D.L., Goldman, R.D., and Leinwand, L.A. 1998. Isolation of mitochondria from cells and tissues. In Cells: A laboratory manual (ed. D.L. Spector et al.), pp. 41.41-41.47. Cold Spring Harbor Laboratory Press, Cold Spring Harbor, NY.

Su, M.A., Trenor, C.C., Fleming, J.C., Fleming, M.D., and Andrews, N.C 1998. The G185R mutation disrupts function of the iron transporter Nramp2. Blood 92: 2157-2163.

Tarbutt, R.G. and Cole, R.J. 1972. Foetal erythropoiesis in genetically anaemic, flexed-tailed $(f / f)$ mice. Cell Tissue Kinet. 5: 491-503.

Thompson, M.W., McCulloch, E.A., Siminovitch, L., and Till, J.E. 1966. The cellular basis for the defect in haemopoiesis in flexed-tailed mice. I. The nature and persistance of the defect. Br. J. Haematol. 12: 152-160.

van Waveren Hogervorst, G.D., van Roermund, H.P.C., and Snijders, P.J. 1987. Hereditary sideroblastic anaemia and autosomal inheritance of erythrocyte dimorphism in a Dutch family. Eur. J. Haematol. 38: 405-409.

Wevrick, R., Barker, J.E., Nadeau, J.H., Szpirer, C., and Buchwald, M. 1993. Mapping of the murine and rat Facc genes and assessment of flexed-tail as a candidate mouse homolog of Fanconi anemia group C. Mamm. Genome 4: 440-444.

Xu, Y., Mayor, J.A., Gremse, D., Wood, D.O., and Kaplan, R.S. 1995 High-yield bacterial expression, purification, and functional reconstitution of the tricarboxylate transport protein from rat liver mitochondria. Biochem. Biophys. Res. Commun. 207: 783-789. 


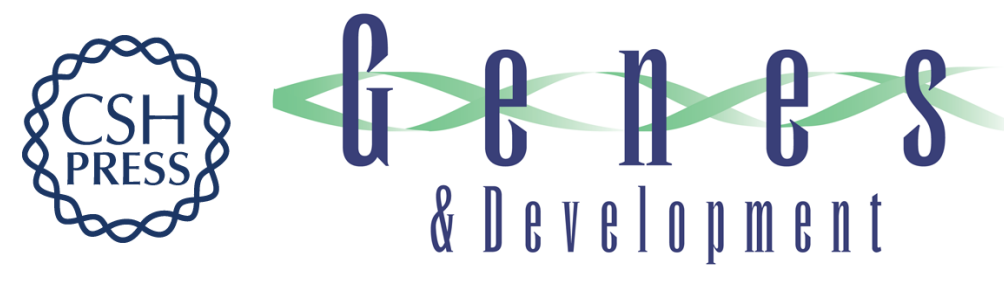

\section{A mutation in a mitochondrial transmembrane protein is responsible for the pleiotropic hematological and skeletal phenotype of flexed-tail $(f / f)$ mice}

Mark D. Fleming, Dean R. Campagna, Judith N. Haslett, et al.

Genes Dev. 2001, 15:

Access the most recent version at doi:10.1101/gad.873001

$\begin{array}{ll}\text { References } & \begin{array}{l}\text { This article cites } 31 \text { articles, } 10 \text { of which can be accessed free at: } \\ \text { http://genesdev.cshlp.org/content/15/6/652.full.html\#ref-list-1 }\end{array}\end{array}$

License

Email Alerting Receive free email alerts when new articles cite this article - sign up in the box at the top Service right corner of the article or click here.

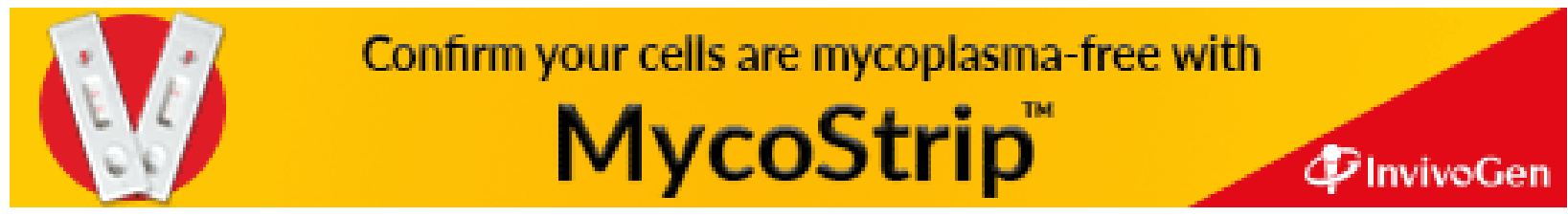

